\title{
Leprosy and Tuberculosis in Kenya
}

\author{
D. L. LEIKER \\ Royal Tropical Institute, Amsterdam, Netherlands \\ (Temporary Member of the Medical Research Centre, Nairobi, Kenya) \\ Y. OTSYULA \\ East African Leprosy Research Centre, Alupe, Kenya \\ M. ZIEDSES DES PLANTES \\ Government Leprosarium, Alupe, Kenya
}

\section{DISTRIBUTION OF LEPROSY}

Leprosy is endemic in most, if not all, parts of Kenya. The prevalence of the disease, however, varies considerably. Ross Innes (1948) found in surveys in West Kenya prevalence rates of more than $3 \%$, in Coastal Areas $0.7 \%$ and in parts of Central Kenya only $0.1 \%-0.4 \%$. Harden Smith (1957) found marked differences in prevalence rates in surveys in the western parts of the country. The numbers of patients registered in treatment centres near Lake Nyanza and near the Uganda border are high; the numbers are low in East Kakamega, in the Nandi territory and in the Kipsigis area. No patients are registered in Kisii.

It appears that there is a rather well defined border between areas of high and of low prevalence of leprosy. This border runs approximately from Mount Elgon southwards to Kisii. In the south this border coincides with the division between the Nilotic Jaluo and the Bantu Kisii, and this suggests a tribal factor. In the north, however, the border line divides the Abaluhia territory showing that possible tribal factor is of secondary importance.

PREVIOUS STUDIES ABOUT THE RELATIONSHIP BETWEEN LEPROSY AND TUBERCULOSIS

Grounds (1960) has compared the numbers of leprosy patients on registers in treatment centres in South Nyanza with the numbers of registered tuberculosis paitents. He found that where numbers of registered leprosy patients were high, the numbers of registered tuberculosis patients were low and vice versa. The differences were highly significant statistically. It seems that the differences in prevalence of leprosy in West Kenya can be adequately explained by differences in prevalence of tuberculosis.

Most leprologists agree that there is an epidemiological relationship between leprosy and tuberculosis but about the nature of this relationship much uncertainty still exists. The hypothesis of a simple antagonism between the 2 diseases seldom fits the facts. In New Guinea (Leiker, 1960) a significant correlation was found between the prevalence of tuberculosis and of leprosy. The differences in prevalence rates, however, were correlated with differences in type and age distribution. Such differences are not conspicuous in West Kenya. Secondly, it is not certain that numbers of leprosy patients and tuberculosis patients registered in treatment centres truly represent the prevalence rates of the 2 diseases. It was found that the staff of treatment centres is insufficiently trained in the diagnosis of leprosy with the result that among the registered patients several were found who did not have leprosy. It was also found in surveys that many patients do not attend treatment centres. Obviously the diagnostic facilities in regard to tuberculosis are limited in many of the rural treatment centres. Early, subclinical, closed cases of tuberculosis can easily be missed. Further studies of the situation are therefore indicated.

LEPROSY SAMPLE SURVEYS

It is already 10 years since the last leprosy 
surveys in Abaluhia territory were carried out. Two new sample surveys were carried out in order to verify that the well defined border between areas of high and low prevalence of leprosy still exists.

The population surveys were preceded by a house to house census. The first survey was carried out at Mukweya, North Wanga location, Kakamega district. In 1957 Harden Smith found a prevalence of leprosy of $1.2 \%$. About 450 patients are registered in the local treatment centre. In the present survey 1,089 people were examined and a total of 19 patients were found, giving a prevalence of $1.7 \%$.

The second survey was carried out at Musena, Isukha location, Kakamega district, only about 30 miles east of the previous survey. In 1957 Harden Smith et al. found only a few patients with leprosy. Very few patients are registered in the local treatment centre.

In the present survey 650 people were examined and only one was found to have leprosy, a prevalence of $0.15 \%$. It is concluded that the situation has not changed essentially since 1957.

Special skin clinics were held in various Health Centres and dispensaries in Southern Nyanza. In the Jaluo territory many leprosy patients, including many new ones, were seen. In the Health Centre at Kisii no leprosy patients were seen and the local attendant claimed that there is no endemic leprosy in Kisii.

The findings confirm the existence of a well defined border between areas of high and of low prevalence of leprosy in West Kenya.

FURTHER CORRELATION STUdIES OF LEPROSY AND TUBERCULOSIS

Large scale intensive leprosy surveys have not been carried out recently in West Kenya. No attempt was therefore made to base this study on absolute prevalence rates. The numbers of registered patients in treatment centres and the results of previous sample surveys, however, permit the division of the area into parts with a definitely high prevalence of leprosy, an intermediate prevalence and a definitely low prevalence of this disease.
In regard to the prevalence of tuberculosis, instead of basing this study on numbers of registered tuberculosis patients, an analysis was made of the large number of tuberculin tests in school children carried out by teams of the Tuberculosis Unit.

The tests were carried out with 5 T.U. P.P.I)., according to the Mantoux technique. Size frequency distribution histograms were made. The histograms of tests in individuals of various age groups and from various areas were bimodal. From the size distribution of the reactions it was concluded that most reactions of less than $10 \mathrm{~mm}$. are non specific and that most reactions of $10 \mathrm{~mm}$. or more are caused by tuberculosis infection. The results are summarized in Table 1.

In 6,340 Jaluo children of 5-14 years, living in an area with a definitely very high prevalence of leprosy the tuberculin index is $14 \%$.

In 12,819 children of the same age group, living in Kakemega district in areas where the prevalence of leprosy is much lower, the tuberculin index is $11 \%$.

In 2,2:31 children of the same age group, living in Kisii where the prevalence of leprosy is definitely very low or the disease is not endemic, the tuberculin index is only $8 \%$.

The findings do not show a clear correlation between the prevalence of leprosy and of tuberculosis. The tuberculin index is even somewhat higher in the area with the highest prevalence of leprosy.

The findings do not exclude the possibility that tuberculosis has influenced the leprosy situation. The effect of tuberculosis may well be obscured by other factors influencing the epidemilogy of leprosy. It is, however, concluded that the distribution of tuberculosis alone does not offer a satisfactory explanation for the distribution of leprosy in West Kenya.

Assessment of the influence of tuberculosis in Kenya is difficult because it cannot be based on prevalence rates of leprosy only. Information about the type distribution of leprosy is needed and such data are not available. Studies in New Guinea (Leiker, 1960) suggest that mild, high resistant tuberculoid leprosy may be 
Prevalence of leprosy and reactions to 5 T.U.P.P.D. in children in West Kenya

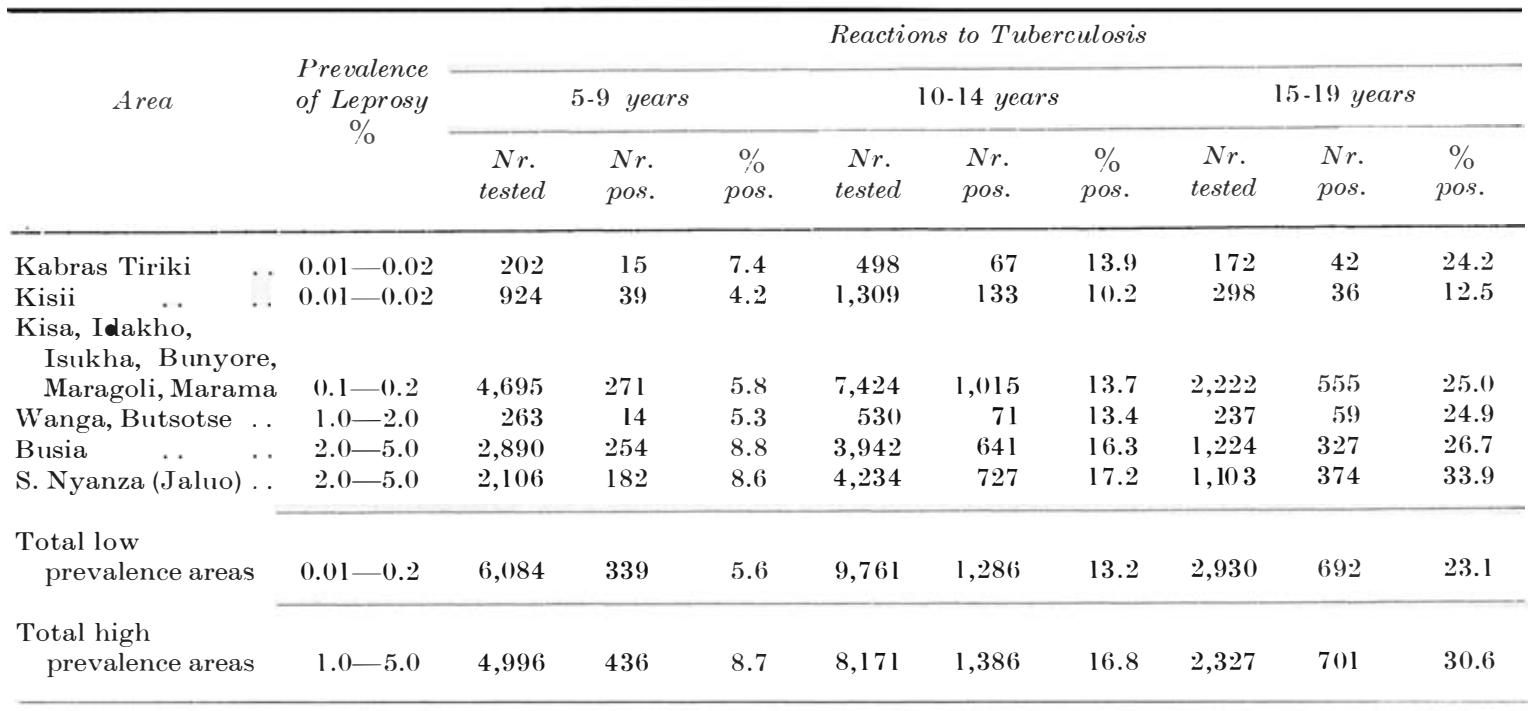

prevented by previous tuberculosis infection and that progressive forms of leprosy are not prevented. In Kenya the proportion of high resistant tuberculoid patients is lower than in parts of West Africa with a lower tuberculin index, and much lower than in New Guinea in areas with a very low tuberculin index.

A high proportion of the tuberculoid patients in Kenya are low resistant tuberculoid. It is likely that many mild tuberculoid patients were prevented by tuberculosis infection.

In the last decades there have been marked changes in the age distribution of the population of West Kenya. Due to a decrease in the death rate the proportion of children in the community has become very high. Children are, on the average, more susceptible to a mild tuberculoid form of leprosy than adults. There is no evidence of a greater susceptibility to progressive forms of leprosy. One would expect an epidemic of mild tuberculoid leprosy in children. The incidence of leprosy in children is high, but a large proportion of the patients are low resistant tuberculoid or more progressive forms of leprosy. Probably many mild tuberculoid patients were prevented by tuberculosis infection.

\section{OTHER FACTORS}

The possibility that the distribution of leprosy is related to the history of the disease has to be considered. It is of ten assumed that leprosy is a very old disease in Kenya but there is no proof that this is true.

Doubtless, leprosy has been introduced fairly long ago into Coastal areas, possibly by invaders from across the sea or from the North. Bodily contact between invaders and members of tribes living more towards the interior has been limited. It is likely that the disease has spread only slowly, mainly along trade routes. It is rather significant that, for example, the prevalence of leprosy is higher in Taveta which is an old caravan station than in the surrounding area (Ross Innes, 1948). The best explanation for foci of leprosy in Central Kenya, e.g., in the Wakamba area and near Mount Kenya, is more intensive and prolonged contact with the Coast.

The history of leprosy in West Kenya may be considerably shorter and here the disease may not have been introduced from the Coast. It is more likely that leprosy was introduced by people who have migrated from the direction of the Nile Valley via Uganda to the present sites 
In Kenya occupied by the Jaluo and the Abalukia. The Kisii are of a different origin. In the past, the conditions for a rapid spread of leprosy were not favourable. The density of the population was low. The people did not live in villages but in small scattered clusters of houses. Due to hostility, contact between members of different tribes, even of different clans was rather limited.

Even at present, inter-marriage between members of different tribes is still uncommon. Marriage within the clan or with closely related clans is often preferred to other marriages. Villages are still virtually absent.

It is possible that leprosy has been introduced from the North-West and West, has slowly spread towards the East and is still spreading in this direction. This would explain the sharp border between areas with a high and those with a low prevalence of the disease in Abaluhia territory. It would also explain the recent increase of prevalence from $1.2 \%$ to $1.7 \%$ in this area, and the absence of leprosy in Kisii in a population of different origin.

Tuberculosis spreads more easily than leprosy. Therefore a more even distribution of tuberculosis may be expected. The higher prevalence of tuberculosis in the Jaluo and Abaluhia as compared with the Kisii can be explained by more contact of the former with urban centres. Only relatively few Kisii leave their area to sojourn in the urban centres.

The distribution of leprosy in the whole of Africa is probably closely related to the history of population migrations. It is often assumed that leprosy has originated in Africa. Arguments for this assumption are that recent findings of human fossils strongly suggest that man has originated in Central Africa.

Furthermore, the highest prevalence of leprosy is found in the Central part of the continent. The prevalence becomes gradually less towards the South and is relatively low in North Africa.

A high prevalence of leprosy, however, is not an argument for a long history of the disease. More often a very high prevalence of leprosy points to a rather short history of the disease. In the Pacific (Leiker, 1960) very high pre- valence rates were found in particular in area with a definitely short history of the disease.

The epidemiological picture of leprosy in several parts of Central Africa with a very high prevalence of the disease has much in common with that of the Pacific.

It is also significant that some of the oldest populations of Africa, e.g., Bushmen and Hottentots, do not show a high prevalence of leprosy and do not show evidence of a long history of the disease. The pattern of leprosy in the Pygmies of the Congo suggest a short history.

A more likely explanation for the distribution of leprosy in Africa, compatible with the main direction of migrations, is that leprosy was introduced in the North and has spread southwards. The disease declined in the oldest foci in North Africa as it has in Europe. Leprosy has lingered or was introduced later in some of the more isolated parts, e.g., the Ethiopian Plateau. The disease may still be increasing or may have reached a peak in Central Africa and is probably still on the increase in parts of the Southern half of Africa. It is significant that the highest prevalence rates are found in populations who have been or still are rather isolated. This may be due to local conditions favouring the spread of the disease, but also to a later introduction of leprosy and of tuberculosis.

Accurate, detailed sample surveys, study of the history of leprosy and the history of population migrations are needed for a better understanding of the epidemiology of leprosy in Africa and re-surveys of the sample areas are needed for assessment of the trend of the disease.

\section{SUMMARY}

Regional differences in prevalence of leprosy in Kenya, varying from $0.1 \%$ to more than $3 \%$, have previously been explained by differences in prevalence of tuberculosis. The validity of these studies, based on numbers of registered tuberculosis and of leprosy patients is doubted.

In this study the tuberculin reactions in large numbers of children in areas with a definitely high prevalence of leprosy are compared with those in areas with a definitely low prevalence 
of the disease. No correlation was found between leprosy index and tuberculosis index.

It is concluded that in West Kenya the distribution of tuberculosis alone does not offer a satisfactory explanation for the distribution of leprosy. It is likely that tuberculosis has had some influence on the epidemiology of leprosy but the effect is obscured by other factors. The distribution of leprosy may be related to the history of the disease, in Africa and in the country itself. Leprosy probably did not originate in Africa but was first introduced in North Africa. The main direction of spreading has been from North to South. In West Kenya leprosy was probably introduced by people who migrated from the Nile Valley via Uganda into West Kenya. The disease is still spreading from West to East.

\section{ACKNOWLEDGEMENTS}

Our thanks are due to 1)r. J. C. Likimani, Director of Medical Services, Kenya, for permission to publish this article, to Dr. J. O. W. Angawa and Mr. J. Poti of the Tuberculosis Unit, Nairobi, Kenya, for making the data of the tuberculin surveys available for analysis.

\section{REFERENCES}

1. Grounds, J. J. Leprosy and Tuberculosis. A statistical relationship. .J. Trop med. Hyg. (1964), 67, 1 .

2. HARden smith. Report to the Ministry of Health, Kenya, 1957 (not published).

3. LEIKER, D. L. Epidemiological and immunological surveys in Netherlands New Guinea. Lep. Rev. (1960), 31, 4, 241.

4. Ross innes, J. Leprosy in Kenya. E. Afr. med. .J (1949), 26, 2, 1-4. 